\title{
THE EFFECT OF PHOTOPERIOD ON WHITE PINE SEEDLING GROWTH
}

\author{
BY D. P. FOWLER ${ }^{1}$
}

\begin{abstract}
White pine seedlings from freshly germinated seed were subjected to different photoperiods and light intensities for a period of nine months. The photoperiods consisted of normal, normal plus eight hours, and continuous day length while the supplementary light intensities were 25-50 foot candles and 200-400 foot candles. Three levels of soil fertility obtained from mixtures of acid sand and white pine humus were also tested.

Observations were recorded over the nine month period and at the termination of this time data from the following measurements were obtained: hypocotyl length, top length, root length, stem diameter, and oven-dry weight.

Hypocotyl length was found to be independent of soil fertility, whereas both continuous light and light of high intensity caused seedlings to have short hypocotyls.

Top length and root length were found to be dependent upon soil fertility as well as upon photoperiod but were independent of light intensity. Continuous light caused the greatest root length whereas eight hours additional light caused the greatest crown length.

Stem diameter was found to be dependent upon soil fertility, photoperiod and light intensity. No significant differences in this respect were found between photoperiods consisting of eight hours additional light and continuous light. The greatest stem diameter resulted from high light intensity.

Oven-dry weight was found to depend upon soil fertility, photoperiod, and light intensity. The richer the soil, the longer the photoperiod, and the greater the light intensity, the greater was the weight of the seedlings produced.

\section{INTRODUCTION}

Since the early nineteen twenties when Garner and Allard (1922) first demonstrated the phenomenon of photoperiodism in plants, research and development in this field have progressed rapidly. Researchers have substantiated the original findings, determined which wave lengths of light cause photoperiodic responses and are proceeding toward an understanding of the mechanisms and reactions. For a detailed review of this literature the reader is referred to Murneek and Whyte (1948).

Although early studies of photoperiodism were concerned only with the effects of photoperiod on the initiation of flowering in plants, more recent studies have widened the scope of photoperiodism to include a large number of growth responses.

Foresters and researchers in the forestry field, though invariably conservative in the speed with which they pursue new fields, have also accumulated a considerable amount of information. Trees, as usual, have proved to be

\footnotetext{
${ }^{1}$ Southern Research Branch, Ontario Dept. of Lands and Forests, Maple, Ont. A short personal biography is in For. Chron. 35: 30. Cost of this publication is shared by the Ontario Dept. of Lands and Forests and the C.I.F.
} 
very similar in this respect to most other plants. Day length, or more accurately the length of the dark period, has been shown to affect such diverse processes as seed germination, stem elongation, needle length, cambial activity, intiation and breaking of dormancy and in a few instances flowering. For a review of the literature pertaining to woody plant species the reader is referred to Wareing (1949), Downs (1958), Pauley (1958), and Wareing and Black (1958).

Let us consider briefly some of the information available concerning coniferous tree species. Pinus: Kramer (1936) was able to grow P. taeda seedlings all winter by increasing the day length to $14 \frac{1}{2}$ hours but found that growth was even better when continuous light was used. Wareing (1950, 1950A and 1951) found that he was not able to maintain continuous growth in $P$. sylvestris regardless of the light treatments used, but that long photoperiods did increase the seedling growth. He reported that a 20 -hour photoperiod produced the greatest stem elongation, leaf number, larger terminal bud and a lesser tendency to produce dwarf shoots in first year seedlings than light periods of a longer or shorter duration. With seedlings older than one year Wareing found that though internode elongation was favoured by long days the number of leaves, which are predetermined in the bud, was not increased. In these same seedlings long days increased the length of needles and prolonged the period in which xylem tissue was produced. Wareing was able to induce buds of $P$. sylvestris in a state of summer dormancy to grow with long photoperiods but was unable to break the dormancy of winter buds regardless of photoperiod unless the seedlings received a chilling period. Gustafson (1938) succeeding in overcoming the chilling requirements in $P$. resinosa by subjecting the unchilled plants to 16 -hour days.

Vaartaja (1954) reported that $P$. sylvestris seedlings from high latitudes grew better under continuous light than seedlings from lower latitudes whereas the reverse was true when the seedlings were raised in short days. Seedlings of both latitudes produced more growth under long day conditions. Vaartaja suggested that heritable differences in response to photopheriod exist in trees from these different latitudes. Similar responses were reported by Pauley and Perry (1954) from their work with poplars.

Pinus taeda, $P$. virginiana, and $P$. rigida showed "considerable" growth increase, $P$. strobus, $P$. banksiana and $P$. elliottii showed moderate growth increase and $P$. mugo showed no growth increase when subjected to extended light periods (N.E.F.E.S., 1958).

Picea: Vaartaja (1954) and Senn (1957) reported photoperiodic growth responses for $P$. abies when raised under long days whereas work carried out at the Northeastern Forest Experiment Station (N.E.F.E.S., 1958) indicated no increase in growth for this species. Senn was also successful in increasing the growth of $\boldsymbol{P}$. glauca and $\boldsymbol{P}$. mariana seedlings with long photoperiods.

Larix: Vaartaja (1954) found that Larix sibirica responds to continuous light. Wareing (1958) reported that $L$. decidua even in a state of winter dormancy can be induced to grow with long days.

Pseudotsuga: Irgens-Möller (1957) reported that long photoperiods hastened the bud bursting of $P$. menziesii from high elevations while they had 
little effect on low elevation seedlings. High night temperatures apparently eliminate the need for long days in seedlings from high elevations.

An interesting aspect of these photoperiodic responses is the extremely low light intensities that were required. A light intensity in the order of 25-75 foot candles is sufficient to bring about these responses. In some woody species a light intensity of 1 or 1.5 foot candles is all that is required (Kramer, 1937; Pauley and Perry, 1954). It is also of interest that very specific wave lengths of light cause these photoperiodic responses. There exist two regions of the light spectrum, one in the red and the other in the far-red portion, which have a maximum effect. The reactions in many instances have been shown to be reversible in that radiation from the far-red portion of the spectrum causes a reaction which can be reversed by light from the red portion and vice versa. Because of this, the effectiveness of a light source to cause a specific growth response is dependent upon the ratio of red to far-red light emitted by that light source (Downs, 1958).

Such promising results have been demonstrated with respect to the effect of photoperiod on the growth and development of tree seedlings that it was decided to carry out an experiment to determine if controlled photoperiods could be used successfully to stimulate the growth of young Pinus strobus seedlings raised in a greenhouse. Information obtained from this experiment would then be immediately applicable to the raising of valuable white pine hybrid seedlings produced in conjunction with the white pine breeding program carried out at the Southern Research Station, Maple, Ontario. The results might also serve as a partial basis for further study and experimentation concerning the value of added light in nurseries.

\section{Materials and Methods}

In the fall of 1957 fresh white pine seed from Ontario site region 7 (Hills, 1959) was obtained and stored at $40^{\circ} \mathrm{F}$. On October 24 and 25,1957 , the seed coats were removed from approximately 1,800 seeds to eliminate dormancy requirements (for technique see Fowler, 1959). The naked seeds were then placed on moist acid sand in petri dishes. When a seed germinated (November 1-11) it was immediately moved into a greenhouse where it was planted into a flat containing an appropriate soil mixture and subjected to different light conditions.

The soils and light conditions varied as follows:

Normal light

humus

$1 / 2$ humus, $1 / 2$ sand

$1 / 3$ humus, $2 / 3$ sand

Normal light plus 8 hours low intensity light humus $1 / 2$ humus, $1 / 2$ sand

$1 / 3$ humus, $2 / 3$ sand

Normal light plus 8 hours high intensity light humus

$1 / 2$ humus, $1 / 2$ sand

$1 / 3$ humus, $2 / 3$ sand 
Normal light plus continuous low intensity light humus

$1 / 2$ humus, $1 / 2$ sand

$1 / 3$ humus, $2 / 3$ sand

Normal light plus continuous high intensity light humus

$1 / 2$ humus, $1 / 2$ sand

$1 / 3$ humus, $2 / 3$ sand

Five chambers of equal size were constructed within the greenhouse, so that plants grown within each chamber would receive similar amounts of natural daylight. The chambers were placed east-west across the greenhouse and were separated by partitions that eliminated the passage of light from one chamber to another. The lighting in each chamber was maintained separately from the other chambers.

Low intensity additional light was supplied by 40 -watt incandescent bulbs which yielded 25-50 foot candles of visible light at plant level. The higher light intensity was supplied by eight foot fiuorescent tubes which yielded 200-400 foot candles of visible light at plant level. The fluorescent lighting consisted of a bank of two light tubes, one a cool white and the other a pink, as it was felt that light from these two tubes combined to simulate natural light more closely than light from a cool white tube alone (General Electric, 1950).

The plants in all light treatments received similar amounts of natural daylight. The natural day length, as determined by the interval between sunrise and sunset, at Maple, Ontario (latitude $43^{\circ} 50^{\prime} \mathrm{N}$ ) ranged from approximately 9 to 13 hours during the period of active height growth. The range of the effective natural day length, that is the duration of the light period capable of producing a photoperiodic response, was somewhat greater. The plants receiving eight hours additional light received this light in the middle of the dark period ( 8 p.m. -4 a.m.) while the plants with the continuous light treatment received additional light at all times throughout the duration of this experiment.

The three soils used in this experiment were volumetric mixtures of white pine humus and sand. The humus was obtained from a white pine plantation at Midhurst, Ontario, while the sand used was moderately coarse acid sand from Dorset, Ontario. Each of the three soils was replicated three times for each light treatment. A replication consisted of a flat divided into three compartments each of which contained one of the three soil mixtures. The soils were randomly distributed within the flats.

Twenty-five seeds were planted in each of the three soils in each replication, thus a total of 225 seeds were planted for each light treatment.

During the first month following planting, occasional seedlings succumbed to what appeared to be damping-off fungi and were immediately replaced with freshly germinated seeds. No attempt was made to replace or sterilize the soil from which the dead seedlings were removed.

General observations concerning seedling development were made and recorded throughout the duration of the experiment. 
In August of 1958, approximately 9 months following seed germination, five seedlings were chosen at random from each of the subflats and retained for further study. These seedlings were carefully removed from the soil media and washed clean of any adhering soil particles. The seedlings were then subjected to the following measurements:

1. Length of hypocotyl-measured from the root collar to the base of the cotyledons.

2. Top length-measured from the root collar to the apical growing point.

3. Root length-measured from the root collar to the tip of the longest root.

4. Stem diameter-measured at a point one centimeter above the root collar.

5. Oven-dry weight-determined after the seedlings had been dried to constant weight at $110^{\circ} \mathrm{F}$ in an oven.

\section{RESULTS}

Seedling mortality was not a serious factor in any of the soils or under any of the light treatments tested and in only one instance did a replacement seedling die of damping-off (or other causes) even though no attempt had been made to change or sterilize the soil before the replacement seedling was planted. 5.9 percent of all the seedlings died from damping-off or other causes.

\section{General Observations}

In the early stages of development the seedlings receiving additional light exhibited a phototropic response by bending toward the strongthest supplementary light source available to them. Seedlings receiving the higher light intensity leaned toward the cool white fluorescent tube in preference to the pink.

At two weeks after planting 80 percent of the seedlings receiving continuous high intensity light had developed primary needles. The same stage of development was then reached by 55 percent of the seedlings receiving continuous low intensity light, by 30 percent of those receiving 8 hours additional high intensity light, by 17 percent of those receiving 8 hours additional low intensity light and by only 3 percent of those receiving normal light.

Two months after planting all but two of the seedlings receiving no additional light had formed terminal buds and become dormant. None of the seedlings receiving additional light showed signs of terminal bud formation. Only those receiving continuous light were beginning to develop secondary needles.

Five months after planting all the seedlings receiving only normal daylight had terminal buds and had not broken dormancy, and only two of these had developed secondary needles.

Thirty percent of the seedlings receiving 8 hours additional light had formed terminal buds while only 8 percent of the continuously illuminated seedlings had formed terminal buds. Forty percent of the seedlings receiving 8 hours additional illumination showed secondary needle formation while almost 100 percent of those receiving continuous light had secondary needles.

Nine months following planting the seedlings receiving only normal daylight were virtually in the same condition that they had been four months 
earlier. Except for a few seedlings which were growing under the eight hours additional low intensity light, all seedlings had formed terminal buds and ceased to grow in height. The secondary needles on seedlings receiving continuous light treatments were abnormally long.

\section{Measurements}

The average results are presented in Table 1 and Figure 1.

Values of $F$ obtained by an analysis of variance made on the measured data are presented in Table 2.

\section{Discussion}

Increased photoperiod produced greater top and root elongation in $P$. strobus seedlings but in no instance was growth continuous. In all cases height growth was finally terminated by the formation of a resting bud. Long days delayed the cessation of height growth and stimulated the formation and growth of secondary needles. These findings are in agreement with those of Wareing (1950) in his work with $P$. sylvestris, but differ in that continuous light was most effective in producing these responses.

While $P$. strobus seedlings raised under artificially extended photoperiods by the Northeastern Forest Experiment Station (N.E.F.E.S., 1958) showed only "moderate" growth increases, the response of the seedlings in this experiment was considerable. This divergence of results very likely originates from the fact that seeds of a more northern source were used in this experiment. The white pine of this higher latitude may have been subjected to centuries of natural selection under conditions of long summer photoperiods and thus would be expected to respond better to increases in day length. This argument is in agreement with the findings of both Vaartaja (1954) and Pauley and Perry (1954).

The hypocotyl length of white pine seedlings is apparently independent of soil fertility and duration of the light period. During the period of growth prior to the time when the seedlings develop full cotyledon size they evidently receive their nutrients largely from the seed. Continuous light and high intensity light (200-400 f.c.) caused the seedlings to "harden up" faster possibly by a more rapid completion of growth of the hypocotyl or by the formation of shorter and heavier cells.

Top length and root length are strongly controlled by photoperiod, as well as by the fertility of the media in which the seedlings are grown. Light intensity had little effect on either the top or root length. The duration of the photoperiod yielded significantly different results for both top length and root length, but caused different responses. Eight hours of additional light resulted in the greater top length whereas continuous light caused the greater root length. Wareing (1950) encountered a similar phenomenon with $P$. sylvestris where plants raised under a regime of two separate 4-hour dark periods (24 hour cycle) produced longer shoots but shorter roots than plants raised under a regime of only one 4-hour dark period.

Stem diameter is evidently subject to at least indirect photoperiodic control, but there were no significant differences between the responses to duration of the extended photoperiods. The larger stem diameters produced under the lights of higher intensity are likely the result of extended photoperiod and additional assimilation possible under these lights. 

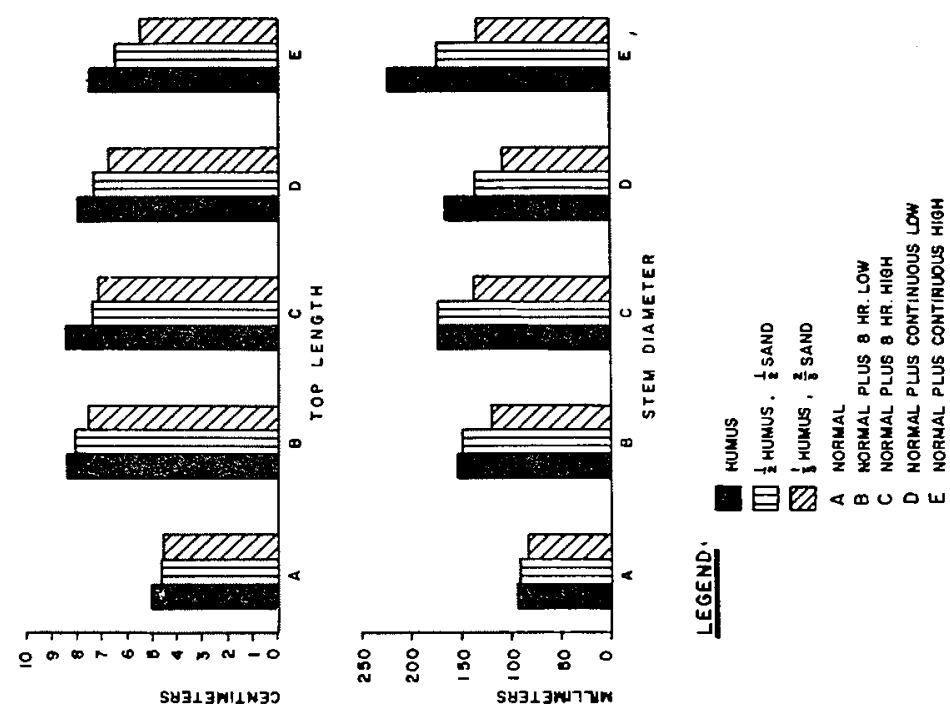

휨웜
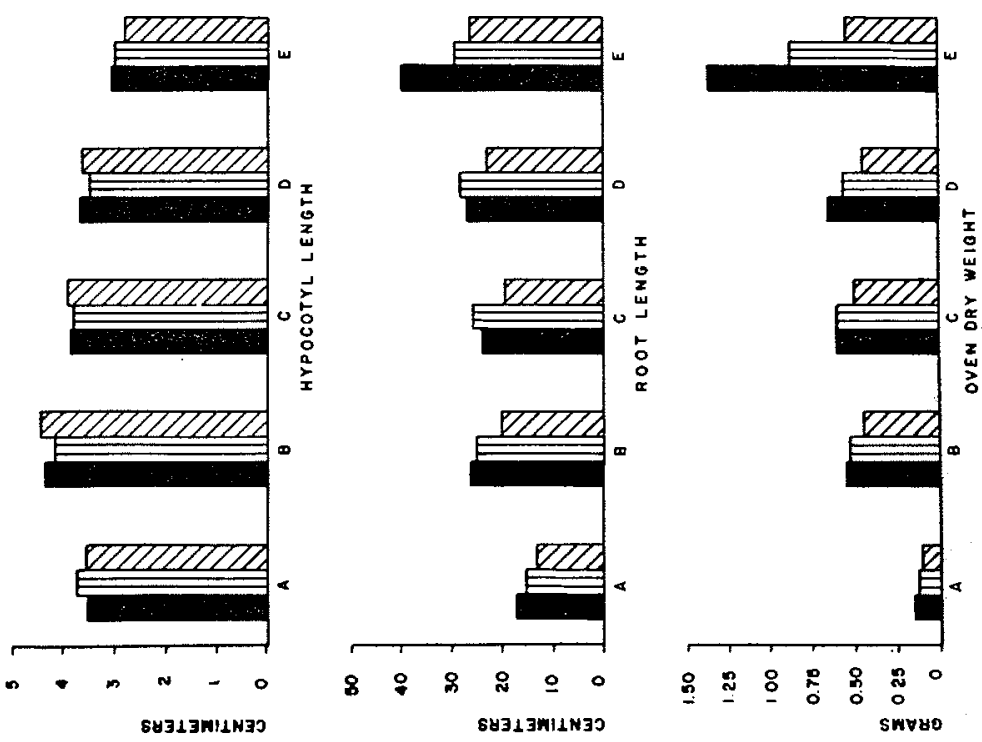
TABLE 1

The Growtin ${ }^{1}$ of 9-Month-Old White Pine Seedlings as Affected by VARIOUS SOILS AND PHOTOPERIODS

\begin{tabular}{|c|c|c|c|c|}
\hline \multirow[b]{2}{*}{ Light Treatment } & \multicolumn{4}{|c|}{ Hypocotyl Length (cm.) } \\
\hline & Humus & $\begin{array}{c}1 / 2 \text { Humns } \\
1 / 2 \text { Sand }\end{array}$ & $\begin{array}{l}1 / 3 \text { Humus } \\
2 / 3 \text { Sand } \\
\end{array}$ & $\mathbf{x}$ \\
\hline Normal & 3.52 & 3.75 & 3.55 & 3.61 \\
\hline Normal plus 8 hours low & 4.38 & 4.01 & 4.45 & 4.28 \\
\hline Normal plus 8 hours high. & 3.83 & 3.79 & 3.91 & 3.84 \\
\hline Normal plus continuous low & 3.70 & 3.53 & 3.68 & 3.64 \\
\hline Normal plus continuous high & $3.18^{\prime}$ & 3.04 & 2.85 & 3.02 \\
\hline $\begin{array}{l}\text { Duration } \\
\text { Normal plus } 8 \text { hours }\end{array}$ & 4.11 & 3.90 & 4.18 & 4.06 \\
\hline Normal plus continuous & 3.44 & 3.29 & 3.27 & 3.33 \\
\hline $\begin{array}{l}\text { Intensity } \\
\text { Low intensity }\end{array}$ & 4.04 & 3.77 & 4.07 & 3.96 \\
\hline High intensity & 3.51 & 3.42 & 3.38 & 3.43 \\
\hline \multicolumn{5}{|c|}{ Root Length (cm.) } \\
\hline Normal & 17.0 & 15.0 & 12.9 & 15.0 \\
\hline Normal plus 8 hours low & 26.3 & 24.7 & 20.1 & 23.7 \\
\hline Normal plus 8 hours high & 23.8 & 25.5 & 19.7 & 23.0 \\
\hline Normal plus continuous low & 26.7 & 27.9 & 22.6 & 25.8 \\
\hline Normal plus continuous high & 40.2 & 29.1 & 26.1 & 31.8 \\
\hline $\begin{array}{l}\text { Duration } \\
\text { Normal plus } 8 \text { hours }\end{array}$ & 25.1 & 25.1 & 19.9 & 23.4 \\
\hline Normal plus continuous & 33.5 & 28.5 & 24.4 & 28.8 \\
\hline Low intensity & 26.5 & 26.3 & 21.4 & 24.7 \\
\hline High intensity & 32.0 & 27.3 & 22.9 & 27.4 \\
\hline & \multicolumn{4}{|c|}{ Oven-Dry Weight (gm.) } \\
\hline Normal & 0.15 & 0.13 & 0.11 & 0.13 \\
\hline Normal plus 8 hours low & 0.55 & 0.53 & 0.45 & 0.51 \\
\hline Normal plus 8 hours high & 0.61 & 0.61 & 0.48 & 0.57 \\
\hline Normal plus continuous low. & 0.66 & 0.57 & 0.45 & 0.56 \\
\hline Normal plus continuous high & 1.37 & 0.88 & 0.55 & 0.93 \\
\hline $\begin{array}{l}\text { Duration } \\
\text { Normal plus } 8 \text { hours }\end{array}$ & 0.58 & 0.57 & 0.47 & 0.54 \\
\hline Normal plus continuous & 1.02 & 0.73 & 0.50 & 0.75 \\
\hline $\begin{array}{l}\text { Intensity } \\
\text { Low inten }\end{array}$ & 0.61 & 0.55 & 0.45 & 0.54 \\
\hline
\end{tabular}

${ }^{1}$ Each value is the mean of 15 seedlings. 
Table 1 (Continued)

\begin{tabular}{|c|c|c|c|c|}
\hline \multirow{2}{*}{ Light Treatment } & \multicolumn{4}{|c|}{ Top Length (cm.) } \\
\hline & Humus & $\begin{array}{l}\text { 1/2 Humus } \\
1 / 2 \text { Sand }\end{array}$ & $\begin{array}{l}1 / 3 \text { Humus } \\
2 / 3 \text { Sand }\end{array}$ & $\overline{\mathbf{x}}$ \\
\hline High intensity . & 0.99 & 0.75 & 0.52 & 0.75 \\
\hline Normal & 5.03 & 4.77 & 4.63 & 4.81 \\
\hline Normal plus 8 hours low & 8.40 & 8.13 & 7.53 & 8.02 \\
\hline Normal plus 8 hours high. & 8.49 & 7.47 & 7.23 & 7.73 \\
\hline Normal plus continuous low & 8.05 & 7.40 & 6.84 & 7.43 \\
\hline Normal plus continuous high & 7.61 & 6.57 & 5.56 & 6.59 \\
\hline Duration & & & & \\
\hline Normal plus 8 hours & 8.45 & 7.80 & 7.38 & 7.88 \\
\hline Normal plus continuous & 7.83 & 6.98 & 6.20 & 7.01 \\
\hline $\begin{array}{l}\text { Intensity } \\
\text { Low intensity }\end{array}$ & 8.23 & 7.72 & 7.24 & 7.73 \\
\hline High intensity & 8.05 & 7.02 & 6.40 & 7.16 \\
\hline & & Stem Dia & ter (mm.) & \\
\hline Normal & .95 & .92 & .84 & .90 \\
\hline Normal plus 8 hours low & 1.55 & 1.51 & 1.21 & 1.42 \\
\hline Normal plus 8 hours high. & 1.73 & 1.73 & 1.37 & 1.61 \\
\hline Normal plus continuous low & 1.67 & 1.35 & 1.08 & 1.37 \\
\hline Normal plus continuous high & 2.24 & 1.76 & 1.33 & 1.78 \\
\hline Duration & & & & \\
\hline Normal plus 8 hours........ & 1.64 & 1.62 & 1.29 & 1.52 \\
\hline Normal plus continuous & 1.96 & 1.56 & 1.21 & 1.58 \\
\hline Intensity & & & & \\
\hline Low intensity & 1.61 & 1.43 & 1.15 & 1.40 \\
\hline High intensity & 1.99 & 1.75 & 1.35 & 1.70 \\
\hline
\end{tabular}

TABLE 2

SUMMARY OF $F$ VALUES

\begin{tabular}{|c|c|c|c|c|c|}
\hline & $\begin{array}{c}\text { Hypocotyl } \\
\text { Length }\end{array}$ & $\begin{array}{l}\text { Top } \\
\text { Length }\end{array}$ & $\begin{array}{c}\text { Root } \\
\text { Length }\end{array}$ & $\begin{array}{c}\text { Stem } \\
\text { Diameter } \\
\end{array}$ & $\begin{array}{c}\begin{array}{c}\text { Oven-Dry } \\
\text { Weight }\end{array} \\
\text { Weint }\end{array}$ \\
\hline ight & & & & & \\
\hline Normal vs Artific & 0.03 & $56.47^{* *}$ & $46.13^{* *}$ & $97.64 * *$ & $139.08^{* *}$ \\
\hline $\begin{array}{l}\text { Duration } \\
8 \text { hours vs. }\end{array}$ & $55.08^{* *}$ & 7.06* & $13.81^{* *}$ & 0.88 & $28.58 *$ \\
\hline $\begin{array}{l}\text { Intensity } \\
\text { High vs. I }\end{array}$ & $-25.9^{\prime}$ & 3.67 & 3.31 & $26.88^{* *}$ & 30.74 \\
\hline Inter & & & & & \\
\hline vs. & 2. & & & & $16.67^{* *}$ \\
\hline oil & 0.54 & $15.76^{* *}$ & $16.97^{*}$ & $48.03 * *$ & $14.30 * *$ \\
\hline
\end{tabular}

* Significant at 5\% level

** Significant at $1 \%$ level 
Oven-dry weight represents the sum of the growth responses in that duration of photoperiod, intensity of light, additional assimilation and nutrient uptake from the media all influence the final weight.

The large growth increases of seedlings resulting from the use of artificially extended photoperiods in comparison to those of seedlings receiving only normal light are undoubtedly exaggerated to a certain degree by the fact that the experiment was carried out in the greenhouse during the winter season. Normal day length at that time of year is much shorter than during the growing season. Thus one would certainly not expect to obtain the same increases in growth found in this experiment with similar experiments carried out in a nursery during the summer.

Photoperiod, though very important, is certainly not the only factor involved in determining the growth of a plant. Temperature, nutrition, cultivation, moisture, etc. also play a role (Pauley and Perry, 1954; Kramer, 1957; Gilbert, 1926). It is evident from the summary presented in Table I that while the sand-humus ratio of the soil is important under all the photoperiods investigated, it becomes more important as other conditions for growth improve (long day and high intensity light).

\section{ConCLUSIONS}

The following conclusions can be made:

1. White pine seedlings, during their first year of growth, respond to an extended photoperiod of light intensities of the order of 25 foot candles or less.

2. None of the photoperiods tested in this experiment caused continuous growth of white pine seedlings though the growth period was greatly increased.

3. The growth of white pine seedlings is dependent upon soil fertility and this dependency increases as other conditions for growth (photoperiod and light intensity) improve.

4. Height growth and root growth are both strongly controlled by photoperiod whereas hypocotyl length, stem diameter, and oven-dry weight are dependent upon both photoperiod and light intensity.

5. The raising of valuable white pine seedlings in a greenhouse during the winter is considerably accelerated by the use of extended photoperiods. It is quite conceivable that similar (though not as large) growth increases can be obtained in the summer. Further research along these lines is needed.

\section{ACKNOWLEDGEMENTS}

The author wishes to thank Professor $T$. Dwight for his assistance in analyzing the data and Dr. C. C. Heimburger for reviewing the manuscript.

\section{REFERENCES}

DOWNS, R. J. 1958. Photoperiodic control of growth and dormancy in woody plants. In The physiology of forest trees. (A symposium). Ronald Press Co., N.Y. 529-537.

FOWLER, D. P. 1959. Rapid germination of white pine seed. For. Chron. 35(3): 203-211.

GARNER, W. W. and H. A. ALLARD. 1922. Photoperiodism, the response of the plant to relative length of day and night. Seience 55: $582-583$. 
GENERAL ELECTRIC CO. 1950. Lamp Bulletin. General Electric Co., Lamp Division. Bull. LD-1. 76 PP.

GILBERT, B. E. 1926. Interrelation of relative day length and temperature. Bot. Gazette. 81: $1-24$.

GUSTAFSON, G. G. 1937. Influence of the length of day on the dormancy of tree seedlings. Plant Phys. 13: 655-658.

HILLS, G. A. 1959. A ready reference to the description of the land of Ontario and its productivity. Ont. Dept. of Lands and Forests. Preliminary Report. 142 pp.

IRGENS-MOLLER, H. 1957. Ecotypic response to temperature and photoperiod in Douglas-fir. For. Sci. 3(1): 79-83.

KRAMER, P. J. 1936. Effects of variation in length of day on growth and dormancy of trees. Plant Physiol, 11: 127-137.

KRAMER, P. J. 1937. Photoperiodic stimulation of growth by artificial light as a cause of winter killing. Plant Physiol. 12: 881-883.

KRAMER, P. J. 1957. Some effects of various combinations of day and night temperature and photoperiod on the height growth of loblolly pine seedlings. For. Sci, 3(1): 45-55.

MURNEEK, A. E. and R. O. WHYTE. 1948. Vernalization and photoperiodism. (A symposium). Chronica Botanica Co., Waltham, Mass. 196 pp.

Northeastern Forest Experiment Station. 1958. Annual Report 1957. U.S. Dept. of Agric., Forest Service, N.E. For. Expt. Station. 9-10.

PAULEY, S. S. 1958. Photoperiodism in relation to tree improvement. In The physiology of forest trees. (A symposium). Ronald Press Co., N.Y. 557-571.

PAULEY, S. S. and T. O. PERRY. 1954. Ecotypic variation of the photoperiodic response in Populus. Jour. Arnold Arb. 35: 167-188.

SENN, H. A. 1957. Some effects of light on the growth of certain woody species. Rep. to Com. on For. Tree Breeding. Mimeo, 5 pp.

VAARTAJA, O. 1954. Photoperiodic ecotypes of trees. Can. Jour. Bot. 32: 392-399.

WAREING, P. F. 1949. Photoperiodism in woody species. Forestry, 22(2): 211-221.

WAREING, P. F. 1950. Growth studies in woody species I. Photoperiodism in first-year seedlings of Pinzs silvestris. Physiol. Plant. 3: 258-276.

WAREING, P. F. 1950A. Growth studies in woody species II. Effect of day-length on shootgrowth in Pinus silvestris after the first year. Physiol. Plant. 3: 300-314.

WAREING, P. F. 1951. Growth studies in woody species III. Further photoperiodic effects in Pinzts silvestris. Physiol. Plant. 4: 41-56.

WAREING, P. F. and M. Black. 1958. Photoperiodism in seeds and seedlings of woody species. In The physiology of forest trees. (A symposium). Ronald Press Co., N.Y. 539-556. 